\title{
Effect of Endosulfan and Parathion on Energy Reserves and Physiological Parameters of the Terrestrial Isopod Porcellio dilatatus
}

\author{
Sónia Ribeiro, ${ }^{*}$ J. P. Sousa, ${ }^{*}, 1$ A. J. A. Nogueira, ${ }^{*}$ and A. M. V. M. Soares $\dagger$ \\ *Instituo Ambiente e Vida, Departamento de Zoologia, Universidade de Coimbra, 3004-517 Coimbra, Portugal; †Departamento de Biologia, \\ Universidade de Aveiro, P-3810-193 Aveiro, Portugal
}

Received November 2, 1999; published online May 3, 2001

The in vivo effects of parathion and endosulfan on the isopod Porcellio dilatatus were investigated. Feeding parameters (food consumption and assimilation rates), growth, and energy reserves (glycogen, lipid, and protein contents) of pesticide-exposed isopods were compared with those of control animals. Isopods were exposed to a wide range of concentrations of parathion or endosulfan $(0.1,1,10,25,50,100,250$, and $500 \mu \mathrm{g} / \mathrm{g}$ of food) for 21 days. The route of uptake of the pesticides was through the diet (alder leaves). Results revealed that parathion induces a significant depression of glycogen, lipid, and protein contents. However, no significant effect was observed on either feeding parameters or growth. Animals fed endosulfan-contaminated food had smaller amounts of glycogen and lipid than control animals, while protein levels were similar in all treatments. Endosulfan also induced a significant decrease in food consumption and assimilation rates at the highest concentrations tested. Growth rate was also significantly affected by endosulfan. These results suggest that the isopod $\boldsymbol{P}$. dilatatus is a suitable species for use in toxicity tests and that energy reserves could be used as effect criteria in both laboratory and field studies. (c) 2001 Academic Press

Key Words: glycogen; lipids; protein; feeding; growth; parathion; endosulfan; Porcellio dilatatus.

\section{INTRODUCTION}

Continuous or pulse exposure to pesticides may cause serious problems for nontarget organisms, leading to a number of pathological and disturbed biochemical processes, including changes in energy budgets. The organisms can have direct energy costs to resist the toxicant by avoidance, exclusion, or removal; moreover, they may need energy to repair mechanisms and eventually pathological effects. All these energy expenses reduce the amount of energy left to invest in normal life and, therefore, increase

\footnotetext{
${ }^{1}$ To whom correspondence should be addressed. Fax: + 351239826798. E-mail: jps@zoo.uc.pt.
}

the probability of dying from additional stress (Calow, 1989).

Recently a great deal of attention has been devoted to the use of physiological/energetic processes of nontarget organisms (e.g., feeding parameters, growth, respiration, reproduction and energy allocation mechanisms) as sensitive indicators in situations of toxic stress due to exposure to metals (Donker, 1992; Donker et al., 1993; Drobne and Hopkin, 1994; Khalil et al., 1995) and chemicals (Van Straalen and Verweij, 1991; Mohamed et al., 1992; Van Brummelen et al., 1996a). The ecological relevance of these parameters becomes more clear, since short-term exposures can cause long-term effects in the life cycle of nontarget organisms, although some compounds do not persist long in the soil.

Parathion $(O, O$-diethyl-O-(4-nitrophenyl) phosphorothioate) is an organophosphate insecticide whose main mode of action is the inhibition of AChE, resulting in an accumulation of acetylcholine in the synaptic terminals, and, therefore, a change in the normal transmission of the nervous impulse (Gallo and Lawryk, 1991; WHO, 1996; Ribeiro et al., 1999). In mammals, severe poisoning can stop breathing due to congestion of the lungs and weakness of the respiratory muscles (Eto, 1974; WHO, 1992; Gälli et al., 1994). Because of the high toxicity of parathion to mammals and humans, its use has been prohibited or severely restricted in many countries. Nevertheless, it is still commonly used in some regions of Portugal to control numerous insect pests.

Endosulfan $\quad(6,7,8,9,10,10$-hexachloro-1, 5, 5a, 6, 9, 9ahexahydro-6, 9-methano-2, 4, 3-benzodioxathiepin-3-oxide) is an organochlorine insecticide. This toxicant is a central nervous system poison (WHO, 1988; Naqvi and Vaishnavi, 1993). Acute intoxication may result in neurological manifestations, such as irritability, restlessness, muscular twitching, and convulsions that may end in death. Due to its low persistence in the environment, it is commonly used in Portugal in several cultures (including rice and corn) to control a wide range of insect pests. 
The terrestrial isopod Porcellio dilatatus was chosen to evaluate the ecotoxicity of these pesticides for several reasons: it is quite easy to capture in the field and to maintain in laboratory cultures and it is an important member of the macroarthropod community of the soil. These organisms play an important role in decomposition processes, promoting litter fragmentation and increasing the attack area for fungi and bacteria, and, therefore, promoting microbial degradation. Isopods have also a major role in the mineralization of nutrients necessary for plants, mainly nitrogen and phosphorus (Sutton, 1972; Hopkin, 1991; White et al., 1992; Van Wensem et al., 1993; Van Brummelen et al., 1996a, b).

Soil contamination may affect saprotrophic activities and may thus endanger soil processes (Hopkin and Martin, 1982; Van Straalen and Verweij, 1991; Van Brummelen et al., 1996a, b). For these reasons, terrestrial isopods are suitable candidates to be used as test organisms in both ecological studies and soil ecotoxicological research (Hopkin, 1991; Donker, 1992; Drobne, 1997). In fact, the number of tests with isopods has been increasing in the past few years (Van Straalen and Verweij, 1991; Donker et al., 1993; Léon and Van Gestel, 1994; Drobne and Hopkin, 1994; Crommentuijn et al., 1995; Vink et al., 1995; Van Brummelen et al., 1996a, b; Caseiro, 1997; Ribeiro et al., 1999).

The aims of the present study are to (1) optimize laboratory methodology used to quantify glycogen, lipid, and protein contents in P. dilatatus; (2) quantify physiological and biochemical responses with ecological relevance (feeding, growth, and energy reserves) in the organisms exposed to parathion or endosulfan; and (3) relate data obtained with the biochemical parameters to the physiological status of the animals.

\section{MATERIALS AND METHODS}

\section{Test Organism and Culture Procedures}

The specimens of Porcellio dilatatus used in these experiments were obtained from a laboratory population, composed of animals collected from a dunar system in central Portugal and fed on alder leaves (Alnus glutinosa), previously oven-dried at $60^{\circ} \mathrm{C}$ for $48 \mathrm{~h}$. This diet was chosen because it provides a higher growth rate and better reproductive performance than others, mainly because of its higher nitrogen content (Caseiro, 1997; Sousa et al., 1998). Isopods were kept in plastic boxes covered with a layer of sand previously autoclaved. Humidity was maintained by regular spraying with distilled water and the ventilation in the boxes was ensured by holes made on the box cover.

\section{Experimental Setup}

In independent experiments, 3- to 4-month-old animals were exposed to parathion or endosulfan. Isopods were confined individually in 5-cm-diameter Petri dishes covered with a bottom of plaster of Paris and fed ad libidum weekly with contaminated alder leaves. Both experiments were conducted in a climate room at a temperature of $20 \pm 1^{\circ} \mathrm{C}$ and a light: dark cycle of 16:8 h. The endosulfan stock solution was prepared in ethanol and the parathion stock solution was prepared in distilled water. Pesticide solutions were previously diluted and added to the leaves. Endosulfancontaminated leaves were allowed to dry overnight at room temperature to ensure solvent evaporation. Distilled water was applied to a further batch of leaves which acted as controls. Ingestion of the toxicants was the major exposure route, although direct surface contact may also have contributed to exposure. Concentrations used for both chemicals were $0.1,1,10,25,50,100,250$, and $500 \mu \mathrm{g} / \mathrm{g}$ of food. In each experiment 10 animals were used per treatment; the period of exposure to the insecticides was 21 days.

\section{Feeding and Growth Measurements}

Isopods were weighed at the beginning of the experiment and weekly. The initial weights ranged from 15 to $55 \mathrm{mg}$. One day before the start of the experiment and 1 day after the end animals were left without food to empty their gut. The food offered to the animals was weighed at the beginning of every feeding period ( 1 week). The feces of the animals and the remaining leaf material were removed weekly from the test boxes, dried in the oven $\left(60^{\circ} \mathrm{C}, 48 \mathrm{~h}\right)$ and weighed; then new contaminated food was offered to the animals.

The parameters measured were consumption rate (Cr: $\mathrm{mg}$ food consumed $/ \mathrm{mg}$ animal/day), assimilation rate (Ar: $\mathrm{mg}$ food assimilated/mg animal/day), assimilation efficiency (AE: percentage of assimilated food in relation to the consumed food), and growth rate (Gr: biomass gain/average weight over time).

\section{Energy Reserve Measurements}

At the end of the experiment animals were sacrificed. Several biochemical analyses were performed on each sample: glycogen, lipid, and protein contents. Individual samples were homogenized in $1 \mathrm{~mL}$ of $0.15 \mathrm{M}$ sodium chloride, using an electrical homogenizer equipped with a speed regulator, and centrifuged for $3 \mathrm{~min}$ at $8000 \mathrm{rpm}$. Samples were kept on ice throughout the homogenization process to avoid protein denaturation and stored at $-70^{\circ} \mathrm{C}$ until the biochemical determinations were performed.

\section{Glycogen Determination}

Glycogen was determined using a modification of the method described by Marshall and Orr (1962) based on that of Dubois et al. (1956). Glycogen was separated from soluble sugars by precipitation in the presence of methanol: $10 \mathrm{~mL}$ 
of methanol was added to $0.2 \mathrm{~mL}$ of sample homogenate and shaken on the Vortex mixer. Mixtures were then centrifuged for $15 \mathrm{~min}$ at $3000 \mathrm{rpm}$. Supernatants were discarded, and the precipitates resuspended in $10 \mathrm{~mL}$ of methanol and shaken on the Vortex. Suspensions were centrifuged again and the precipitates were used for glycogen quantification. The sulfuric acid method was then used to quantify glycogen in the samples, since glycogen is hydrolyzed into glucose in the presence of hot sulfuric acid (Kemp and Heijningen, 1954); all samples were evaporated to total dryness in a water bath at $100^{\circ} \mathrm{C}$. The residue was resuspended with $3 \mathrm{~mL}$ of $1.67 \%$ phenol solution and shaken on the Vortex. Then $5 \mathrm{~mL}$ of concentrated sulfuric acid was mixed and heated at $100^{\circ} \mathrm{C}$ in a water bath for $10 \mathrm{~min}$. Finally, the absorbance was measured at $490 \mathrm{~nm}$. Standards ranging from 0 to $100 \mu \mathrm{g}$ of glucose were prepared from a stock solution of $0.1 \%$ glucose and received the same treatment as the samples.

\section{Lipid Determination}

The lipid fraction in the samples was extracted using a modification of the Blight and Dyer (1959) method: $2.5 \mathrm{~mL}$ of methanol was mixed with $0.5 \mathrm{~mL}$ of sample homogenate for $3 \mathrm{~min}$ on a Vortex mixer. Then, $2.5 \mathrm{~mL}$ of chloroform was added and the mixture shaken for another $3 \mathrm{~min}$. Following this, the mixture was centrifuged for $5 \mathrm{~min}$ at $3000 \mathrm{rpm}$ to speed up the sedimentation of solid residues. The sediment was discarded and $1.25 \mathrm{~mL}$ of chloroform and $2.5 \mathrm{~mL}$ of water were added to the supernatant. The mixture was shaken on the Vortex and centrifuged at $3000 \mathrm{rpm}$ for 5 min to speed up the phase separation process. Then, the lower phase was carefully collected with a pipet equipped with a rubber pump. The sample was dried under a nitrogen stream and resuspended with $2 \mathrm{~mL}$ of a 2:1 (v/v) mixture of chloroform:methanol. Total lipids were determined using a modification of the method described by Ahlgren and Uppsala (1991) based on the sulfophosphovanilline method of Zöllner and Kirsch (1962): $0.5 \mathrm{~mL}$ of sample was evaporated in a water bath at $30^{\circ} \mathrm{C}$ under a nitrogen stream. Then $0.5 \mathrm{~mL}$ of concentrated sulfuric acid was added and heated at $100^{\circ} \mathrm{C}$ in a water bath for $10 \mathrm{~min}$. Finally, $2.5 \mathrm{~mL}$ of vanilline reagent was added and the absorbance was measured at $528 \mathrm{~nm}$ after 2 to $3 \mathrm{~h}$. Standards ranging from 0 to $100 \mu \mathrm{g}$ of linoleic acid were prepared from a stock solution of $0.1 \%$ linoleic acid and received the same treatment as the samples.

\section{Protein Determination}

Before protein determination, samples were diluted 1:10 (v/v) with the sodium chloride solution. The concentration of protein in the samples was determined using the Bradford (1976) method adapted to microplate (Herbert et al., 1995):
$250 \mu \mathrm{L}$ of diluted color reagent (Bio-Rad) was added to $20 \mu \mathrm{L}$ of all samples and to standards of bovine serum albumin. After $15 \mathrm{~min}$ the absorption was measured at $595 \mathrm{~nm}$.

\section{Pesticides}

Parathion-ethyl, $98.9 \%$ pure, and endosulfan sulfate, 97.6\% pure, were purchased from Dr. Ehrenstorfer $\mathrm{GmbH}$, Augsburg, Germany.

\section{Statistical Analysis}

Feeding and growth data were analyzed by comparing consumption and assimilation rates of different treatments using analysis of variance (ANOVA); whenever applicable initial biomass of isopods was used as covariable. Growth and energy reserve data were also analyzed using ANOVA. The arcsine transformation was used to achieve normality and homoscedasty when necessary. These were verified by Kolmogorov-Smirnov and Bartlett tests, respectively (Zar, 1984). Lipid content was compared with a KruskalWallis one-way analysis of variance, since no homoscedasticity was met even after data transformation. Post hoc testing was carried out using the Tukey test. A significance level of 0.05 was used for all statistical tests.

\section{RESULTS}

\section{Mortality}

For the control groups no mortality was observed. In the endosulfan experiment no significant mortality was observed even at the highest concentrations. By contrast, in the parathion experiment the mortality increased with the pesticide concentration and reached $100 \%$ at the highest concentrations (Table 1). For this reason, for the sixth, seventh, and eighth treatments with parathion results were not considered in the feeding and growth measurements, since too many individuals had already died. Nevertheless, biochemical analysis were also performed in the dead isopods.

\section{Effect of the Insecticides on Physiological Parameters}

Feeding parameters and growth in P. dilatatus were not significantly affected by parathion at the concentrations considered (0.1-50 $\mu \mathrm{g} / \mathrm{g}$ of food) (Figs. 1-3). Contrastly, endosulfan induced a significant change in both consumption and assimilation rates at the highest concentrations tested $(100,250$, and $500 \mu \mathrm{g} / \mathrm{g}$ of food) (Fig. 1). Moreover, food assimilation efficiency was also significantly affected by this toxicant $(F(8,76)=4.6, P<0.05)$ (Fig. 2). These changes in feeding behavior significantly affected growth rate at the highest concentrations $(F(8,79)=7.07, P<0.05)$ (Fig. 3). 
TABLE 1

Percentage Mortality of Isopods after 21 Days of Exposure to the Toxicants ${ }^{a}$

\begin{tabular}{lcc}
\hline & \multicolumn{2}{c}{$\%$ Mortality } \\
\cline { 2 - 3 } & Parathion & Endosulfan \\
\hline Ctr & 0 & 0 \\
C1 & 10 & 10 \\
C2 & 10 & 10 \\
C3 & 20 & 20 \\
C4 & 30 & 0 \\
C5 & 30 & 0 \\
C7 & 70 & 0 \\
C8 & 100 & 10 \\
\hline
\end{tabular}

${ }^{a} \mathrm{Ctr}$., control group; $\mathrm{C} 1$ to $\mathrm{C} 8$, treatment groups (for concentrations refer to the text).

The average assimilation efficiency values obtained in both toxicants (around 60\%) are much higher than the values reported by Van Straalen and Verweij (1991) and Khalil et al. (1995) for P. scaber (25.6 and 30\%, respectively). Present values are also higher than the value reported for $P$. laevis by Khalil et al. (1995), who found an assimilation efficiency of $42.3 \%$. Nevertheless, these results agree with those obtained for P. dilatatus by Sousa et al. (1998), which averaged $80 \%$ when fed alder leaves.

\section{Effects of Parathion and Endosulfan on Energy Reserves}

Protein, glycogen, and lipid contents of animals cultured in the presence of parathion were significantly lower than those of animals cultured in the absence of the insecticide $(F(8,95)=10.1, \quad P<0.05$ for protein; $F(8,46)=13.9$,
$P<0.05$ for lipids) (Figs. 4A, 4C, 4E). The effect of parathion on glycogen content is concentration dependent, being the differences between the control group and all the other groups statistically significant $(F(8,59)=22.37$, $P<0.05)$. A significant decrease in both glycogen and lipid contents was also noted in endosulfan-treated woodlice $(F(8,56)=10.87, P<0.05$ for glycogen; $F(8,51)=11.23$, $P<0.05$ for lipids) (Figs. 4B, 4D). Protein content, however, was similar to that of the control group $(F(8,89)=1.16$, $P>0.05)$ (Fig. 4F).

\section{DISCUSSION}

Feeding parameters and growth were not affected by parathion at the concentrations considered $(0.1-50 \mu \mathrm{g} / \mathrm{g}$ food). One reason for this absence of effects could be the short exposure period (21 days). Similar results on growth due to short-term exposures were also obtained by Vink et al. (1995) and Crommentuijn et al. (1995). Vink et al. (1995), when exposing P. pruinosus to benomyl and diazinon, observed a significant decrease in weight gain only after 3 and 2 weeks of exposure, respectively. Crommentuijn et al. (1995), analyzing the influence of cadmium on $P$. scaber, observed a significant effect on growth only after 308 days of exposure.

Another explanation for these results may be related to the narrow border that exists between sublethal and lethal effects in isopods. Crommentuijn et al. (1995) calculated a small sublethal sensitivity index (SSI) for cadmium in $P$. scaber, which indicates the closeness of sublethal and lethal concentrations. If this feature is maintained with other chemicals, it may imply that sublethal effects are not always observable if a large spacing factor is used; in the present case no effects were observed at $50 \mu \mathrm{g} / \mathrm{g}$ food, and significant mortality was verified at the next concentration tested $(100 \mu \mathrm{g} / \mathrm{g}$ food).
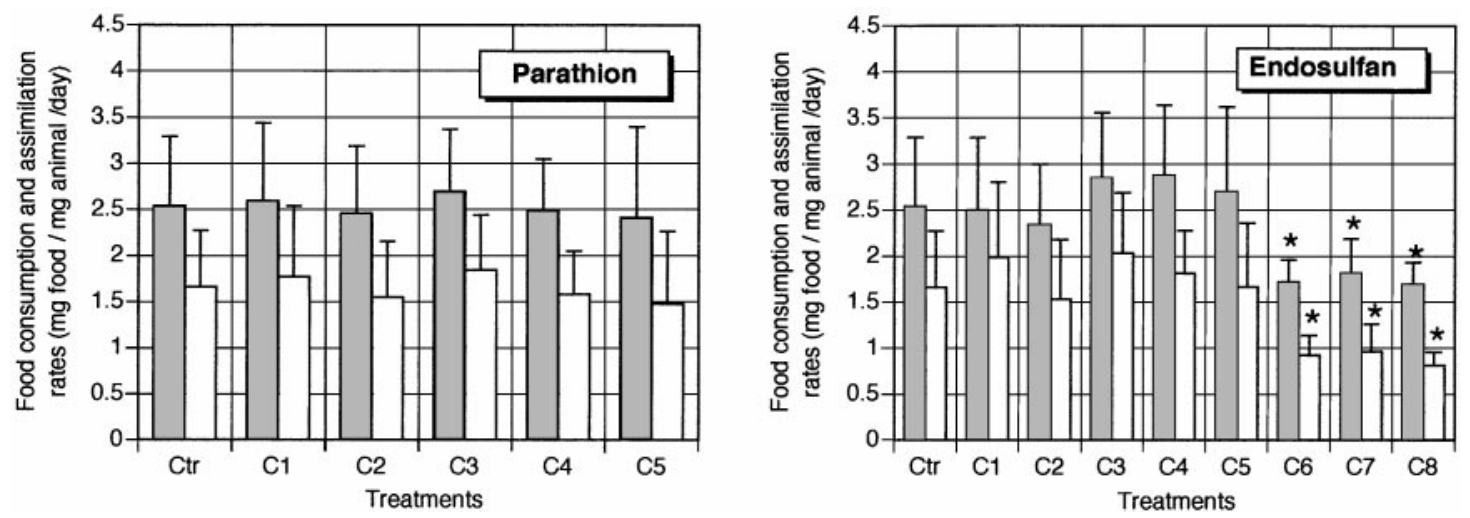

FIG. 1. Food consumption (gray bars) and assimilation (white bars) rates of $P$. dilatatus cultured for 21 days in several concentrations of endosulfan or parathion. Ctr., control group; $\mathrm{C} 1$ to $\mathrm{C} 8$, treatment groups (for concentrations refer to the text). Results are expressed as the mean activity with associated standard deviation bars. Asterisks indicate significant differences in relation to control. 

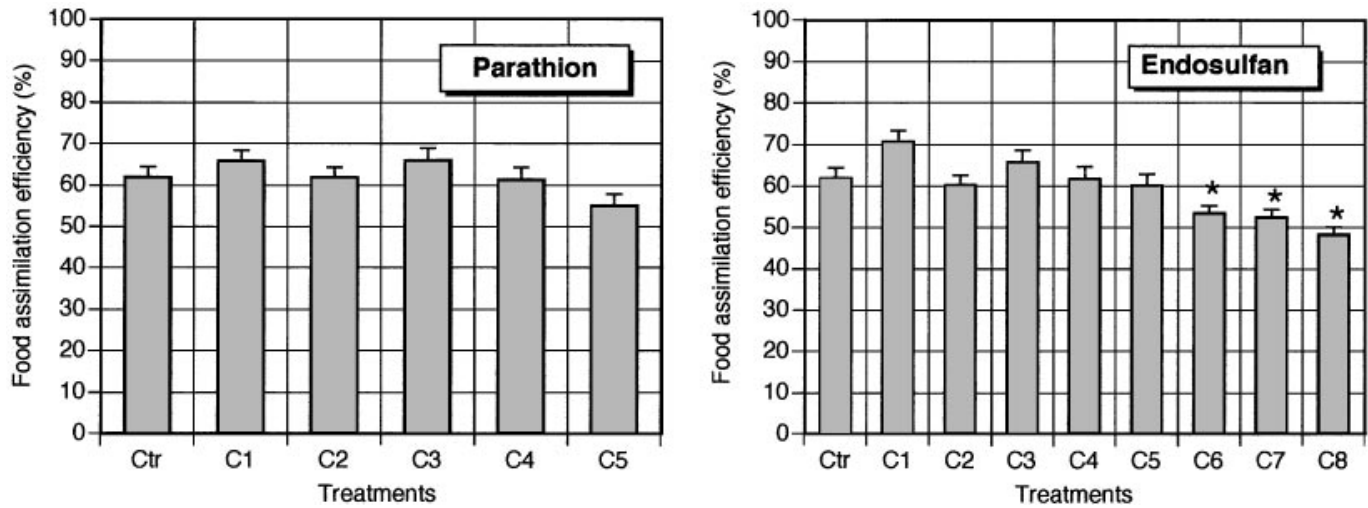

FIG. 2. Assimilation efficiency of $P$. dilatatus cultured for 21 days in several concentrations of endosulfan or parathion. Ctr., control group; $\mathrm{C} 1$ to $\mathrm{C} 8$, treatment groups (for concentrations refer to the text). Results are expressed as the mean activity with associated standard deviation bars. Asterisks indicate significant differences in relation to control.

Endosulfan, on the other hand, significantly affected the same feeding parameters at the highest concentrations. This may indicate a feeding inhibition situation, with the isopods regulating the intake of the pesticide by reducing consumption rates and this affecting thus other related parameters, including growth. This strategy, however, is commonly used to avoid poisoning with heavy metals (Donker, 1992; Drobne and Hopkin, 1994; Bibic et al., 1997); with organic chemicals the strategy is to have high elimination rates to remove the toxicants from the organism. This was verified in $P$. scaber exposed to PAHs (Van Brummelen and Van Straalen, 1996) and in $P$. pruinosus exposed to lindane (Sousa et al., 2000).

The present study indicates that as a result of exposure to the pesticides the biochemical constituents were reduced. A significant decrease in both glycogen and lipid contents was observed at sublethal concentrations of parathion and endosulfan as low as $0.1 \mu \mathrm{g} / \mathrm{g}$ of food.

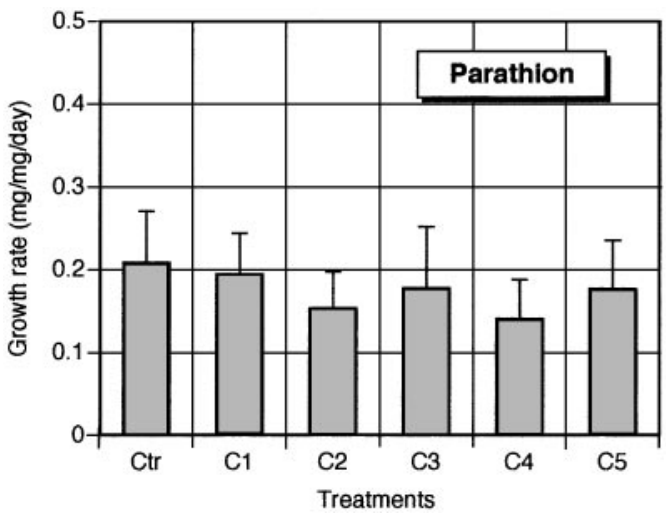

The present results agree with those of Vink et al. (1995), who observed a decrease in these energy reserves in isopods exposed to diazinon. Depletions in glycogen and lipid contents were also verified after exposure to pesticides on mice (Dere and Yanikoglu, 1988, in Naqvi and Vaishnavi, 1993), eels (Sancho et al., 1998), and snails (Rambabu and Rao, 1994) and exposure to metals on isopods (Donker, 1992; Sørensen et al., 1997).

Depletion of glycogen may be due to direct utilization of this compound for energy generation, as a result of pesticide-induced hypoxia. Glycogen is rapidly catabolized, resulting in a rapid decrease in this energy reserve. Lipid content also decreased during exposure to both pesticides due to its use as an energy reserve, parallel to glycogen (Sancho et al., 1998; Rambabu and Rao, 1994).

The decrease in protein content of parathion-intoxicated isopods also indicates a physiological adaptability to compensate for pesticide stress. To overcome the stress

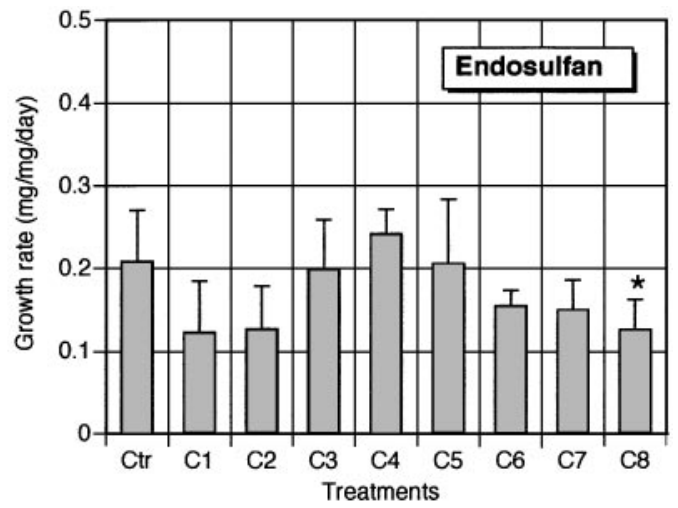

FIG. 3. Growth rate of $P$. dilatatus cultured for 21 days in several concentrations of endosulfan or parathion. Ctr., control group; $\mathrm{C} 1$ to $\mathrm{C} 8$, treatment groups (for concentrations refer to the text). Results are expressed as the mean activity with associated standard deviation bars. Asterisk indicates significant difference in relation to control. 

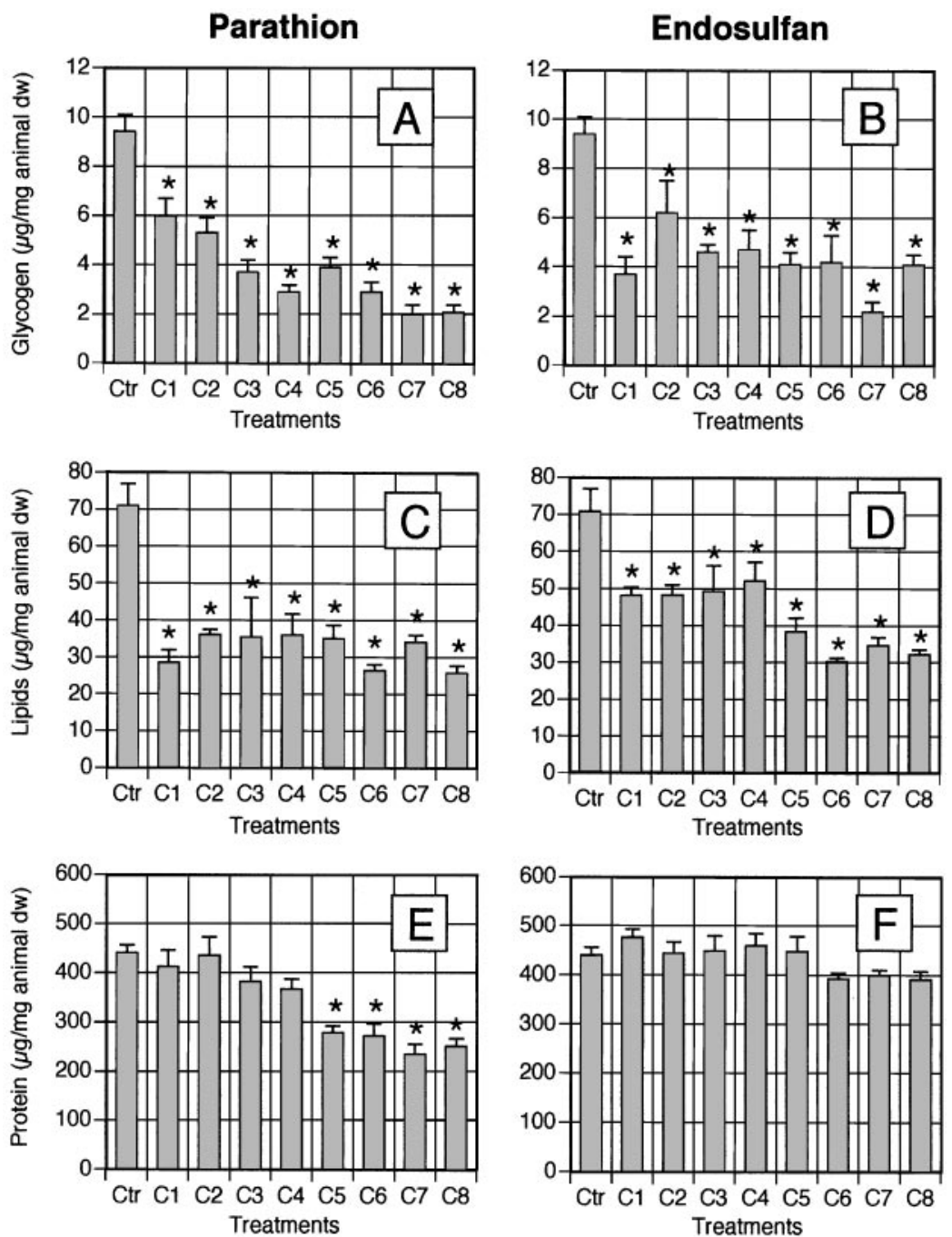

FIG. 4. Glycogen (A, B), lipids (C, D), and protein (E, F) in homogenates of $P$. dilatatus cultured for 21 days in several concentrations of parathion (A, C, E) or endosulfan (B, D, F). Ctr., control group; C1 to C8, treatment groups (for concentrations refer to the text). Results are expressed as the mean activity with associated standard deviation bars. Asterisks indicate significant differences in relation to control.

situation, animals require high energy and this energy demand may have led to the simulation of protein catabolism. Furthermore, this decrease in protein content might also be due to a mechanism of lipoprotein formation, which will be used to repair damaged cell and tissue organelles (Sancho et al., 1998; Rambabu and Rao, 1994). A similar decrease in protein content was also observed by Van Brummelen and Stuijfzand (1993) in P. scaber and O. asellus exposed to benzo(a)pyrene and by Van Brummelen et al. (1996a) in $O$. asellus exposed to fluorene and $\operatorname{benz}(a)$ anthracene; this decrease was followed by a reduction in growth.

On the other hand, in the endosulfan experiment no significant reduction was found in protein levels of insecticide-exposed animals. Perhaps a greater concentration of endosulfan and a higher exposure period would have produced observable effects.

\section{CONCLUSIONS}

The results of the present investigation suggest that the most commonly measured physiological parameters (feeding inhibition-related parameters) may not always provide per se the most sensitive criteria for establishing ecotoxicological effects. This is particularly evident when considering pesticide exposure scenarios, and perhaps the relevance of these parameters could be enhanced by integrating them into physiological mechanistic models that could predict long-term effects on individuals.

On the other hand, biochemical parameters seem quite promising to assess and, to a certain extent, predict the effects of toxicants on nontarget organisms. However, the use of such parameters as biomarkers requires better knowledge of the physiological significance of the changes 
induced by the exposure to pesticides. Furthermore, these results indicate that the isopod $P$. dilatatus is a suitable organism for use in toxicity tests and suggest that it is a sensitive nontarget species that could be used in monitoring studies.

The authors are currently evaluating the effect of other environmental contaminants from different chemical groups on the same type of parameters of $P$. dilatatus to investigate their potential for use both in chemical testing and in specific assessment of soil quality.

\section{ACKNOWLEDGMENTS}

This research was supported by Fundação para a Ciência e a Tecnologia (through Research Project PBIC/C/AGR/2305/95) and a MSc. Research Grant (PRAXIS XXI/BM/10856/97) to Sónia Ribeiro.

\section{REFERENCES}

Ahlgren, G., and Uppsala, L. M. (1991). Lipid analysis of freshwater microalgae: A method study. Arch. Hydrobiol. 121, 295-306.

Bibic, A., Drobne, D., Strus, J., and Byrne, A. R. (1997). Assimilation of zinc by Porcellio scaber (Isopoda, Crustacea) exposed to zinc. Bull. Environ. Contam. Toxicol. 58, 814-821.

Blight, E. G., and Dyer, W. J. (1959). A rapid method for lipid extraction for use in determining vitamin E-lipid ratios. Can. J. Biochem. Physiol. 37, 911-917.

Bradford, M. (1976). A rapid and sensitive method for the quantification of microgram quantities of protein utilising the principle of protein-dye binding. Anal. Biochem. 72, 248-254.

Calow, P. (1989). Physiological ecotoxicology: Theory, practice and application. In 1st European Conference on Ecotoxicology (H. Lokke, H. Tyler, and F. Bio-Rasmussen, Eds.), pp. 23-34. Copenhagen.

Caseiro, I. M. C. (1997). Optimização das condições de cultura de P. dilatatus (Crustacea:Isopoda) para o desenvolvimento de testes laboratoriais. M.Sc. thesis, Universidade do Minho, Portugal.

Crommentuijn, T., Doodeman, C. J. A. M., Van Der Pol, J. J. C., Doornekamp, A., Rademaker, M. C. J., and Van Gestal, C. A. M. (1995). Sublethal sensitivity index as an ecotoxicity parameter measuring energy allocation under toxicant stress: Application to cadmium in soil arthropods. Ecotoxicol. Environ. Saf. 31, 192-200.

Donker, M. H. (1992). Energy reserves and distribution of metals in populations of the isopod Porcellio scaber from metal contaminated sites. Funct. Ecol. 6, 445-454.

Donker, M. H., Zonneveld, C., and Van Straalen, N. M. (1993). Early reproduction and increased reproductive allocation in metal-adapted populations of the terrestrial isopod Porcellio scaber. Oecologia 96, 316-323.

Drobne, D. (1997). Terrestrial isopods: A good choice for toxicity testing of pollutants in the terrestrial environment. Environ. Toxicol. Chem. 16, $1159-1164$.

Drobne, D., and Hopkin, S. P. (1994). Ecotoxicological laboratory test for assessing the effects of chemicals on terrestrial isopods. Bull. Environ. Contam. Toxicol. 53, 390-397.

Dubois, M., Gilles, K. A., Hamilton, J. K., Rebers, P. A., and Smith, F. (1956). Colorimetric method for determination of sugars and related substances. Anal. Chem. 28, 350-356.

Eto, M. (1974). Organophosphorus Pesticides: Organic and Biological Chemistry. CRS Press, Boca Raton, FL.
Gälli, R., Rich, H. W., and Scholtz, R. (1994). Toxicity of organophosphate insecticides and their metabolites to the water flea Daphina magna, the Microtox test and an acetylcholinesterase inhibition test. Aquat. Toxicol. 30, 259-269.

Gallo, M. A., and Lawryk, N. J. (1991). Organic phosphorus pesticides. In Handbook of Pesticide Toxicology (W. J. Hayes, Jr., E. R. Laws, Jr., Eds.), Vol. 2, pp. 917-1123. Academic Press, San Diego.

Herbert, A., Guilhermino, L., de Assis, H. C. S., and Hansen, P.-D. (1995). Acetylcholinesterase activity in aquatic organisms as pollution biomarker. Z. Angewandt Zool. 3, 1-15.

Hopkin, S. P. (1991). A Key to the Woodlice of Britain and Ireland. AIDGAP, London.

Hopkin, S. P., and Martin, M. H. (1982). The distribution of zinc, cadmium, lead and copper within the woodlouse Oniscus asellus (Crustacea, Isopoda). Oecologia 54, 227-232.

Kemp, A., and Heijningen, A. J. M. K. V. (1954). A colorimetric method for the determination of glycogen in tissues. Biochem. J. 56, 646-648.

Khalil, M. A., Donker, M. H., and Straalen, N. M. V. (1995). Long-term and short-term changes in the energy budget of Porcellio scaber Latreille (Crustacea) exposed to cadmium polluted food. Eur. J. Soil Biol. 31, 163-172.

Léon, C. D., and Van Gestel, C. A. M. (1994). Selection of a Set of Laboratory Toxicity Tests for the Effects Assessment of Chemicals in Terrestrial Ecosystems, Discussion Paper. Free Univ. Press.

Marshall, S. M., and Orr, A. P. (1962). Carbohydrate as a measure of phytoplankton. J. Mar. Biol. Assoc. UK 42, 511-519.

Mohamed, A. I., Nair, G. A., Abbas, H. L., and Kassam, H. H. (1992). Effects of pesticides on the survival, growth and oxygen consumption of Helmilepistus reaumuri (Audouin \& Savigny 1826) (Isopoda Oniscidea). Trop. Zool. 5, 145-153.

Naqvi, S. M., and Vaishnavi, C. (1993). Bioaccumulative potential and toxicity of endosulfan insecticide to non-target animals. Comp. Biochem. Physiol. C 105, 347-361.

Rambabu, J. P., and Rao, M. B. (1994). Effect of organochlorine and three organophosphate pesticides on glucose, glycogen, lipid and protein contents in tissues of the freshwater snail Bellamya dissimilis (Müller). Bull. Environ. Contam. Toxicol. 53, 142-148.

Ribeiro, S., Guilhermino, L., Sousa, J. P., and Soares, A. M. V. M. (1999). A novel bioassay based on acetylcholinesterase and lactate dehydrogenase activities to evaluate the toxicity of chemicals to soil isopods. Ecotoxicol. Environ. Saf. 44, 287-293.

Sancho, E., Ferrando, M. D., Fernández, C., and Andreu, E. (1998). Liver energy metabolism of Anguilla anguilla after exposure to fenitrothion. Ecotoxicol. Environ. Saf. 41, 168-175.

Sørensen, F. F., Weeks, J. M., and Baatrup, E. (1997). Altered locomotory behavior in woodlice (Oniscus asellus (L.)) collected at a polluted site. Environ. Toxicol. Chem. 16, 685-690.

Sousa, J. P., Vingada, J. V., Loureiro, S., da Gama, M. M., and Soares, A. M. V. M. (1998). Effects of introduced exotic tree species on growth, consumption and assimilation rates of the soil detritivore Porcellio dilatatus (Crustacea:Isopoda). Appl. Soil Ecol. 9, 399-403.

Sousa, J. P., Loureiro, S., Pieper, S., Frost, M., Kratz, W., Nogueira, A. J. A., and Soares, A. M. V. M. (2000). Toxicokinetics of hydrophobic compounds in isopods. The importance of exposure route on the uptake of Lindane. Environ. Toxicol. Chem. 19, 2563-2577.

Sutton, S. L. (1972). Woodlice. Pergamon, London.

Van Brummelen, T. C., and Stuijfzand, S. C. (1993). Effects of benzo(a)pyrene on survival, growth and energy reserves in the terrestrial isopods Oniscus asellus and Porcellio scaber. Sci. Tot. Environ. Suppl. 1993, 921-930. 
Van Brummelen, T. C., and Van Straalen, N. M. (1996). Uptake and elimination of Benzo $(a)$ pyrene in the terrestrial isopod Porcellio scaber. Arch. Environ. Contam. Toxicol. 31, 277-285.

Van Brummelen, T. C., Van Gestel, C. A. M., and Verweij, R. A. (1996a). Long-term toxicity of five polycyclic aromatic hydrocarbons for the terrestrial isopods. Oniscus asellus and Porcellio scaber. Environ. Toxicol. Chem. 15, 1199-1210.

Van Brummelen, T. C., Verweij, R. A., Wedzinga, S. A., and Van Gestel, C. A. M. (1996b). Polycyclic aromatic hydrocarbons in earthworms and isopods from contaminated forest soils. Chemosphere 32, 315-341.

Van Straalen, N. M., and Verweij, R. A. (1991). Effects of benzo(a)pyrene on food assimilation and growth efficiency in Porcellio scaber (Isopoda). Bull. Environ. Contam. Toxicol. 46, 134-140.

Van Wensem, J., Vrehoef, H. A., and Van Straalen, N. M. (1993). Litter degradation stage as a prime factor for isopod interaction with mineralization processes. Soil Biol. Biochem. 9, 1175-1183.

Vink, K., Dewi, L., Bedaux, J., Tompot, M. H., and Van Straalen, N. M. (1995). The importance of the exposure route when testing the toxicity of pesticides to saprotrophic isopods. Environ. Toxicol. Chem. 14, $1225-1232$.

White, I. D., Mottershead, D. N., and Harrison, S. J. (1992). Environmental Systems: An Introductory Text, 2nd ed., p. 616. Chapman \& Hall, London.

World Health Organization (WHO) (1988). Endosulfan Health and Safety Guide. WHO, Geneva.

World Health Organization (WHO) (1992). Parathion Health and Safety Guide. WHO, Geneva.

World Health Organization (WHO) (1996). Environmental Health Criteria, 63: Organophosphorus Insecticides: A General Introduction. WHO, Geneva.

Zar, J. H. (1984). Biostatistical Analysis. Prentice-Hall, London.

Zöllner, N., and Kirsch, K. (1962). Über die quantitative Bestimmung von Lipoiden (Mikromethode) mittels der vielen natürlichen Lipoiden (allen bekannten Plasmalipoiden) gemeinsamen SulfophosphovanillinReaktion. Z. Ges. Exp. Med. 135, 545-561. 